\title{
Dating of Charcoal Samples from the Polutepe Archeological Site in Azerbaijan
}

\author{
Tufan I. Akhundov ${ }^{1}$, Sahib G. Mammadov ${ }^{2, *}$, Aybeniz A. Ahadova ${ }^{3}$, Afig N. Abdullayev ${ }^{4}$ \\ ${ }^{1}$ Institue of Archaeology and Ethnography, Azerbaijan National Academy of Sciences \\ Baku, Azerbaijan \\ ${ }^{2}$ Institute of Radiation Problems, Azerbaijan National Academy of Sciences \\ Baku, Azerbaijan \\ ${ }^{3}$ Institute of Radiation Problems, Azerbaijan National Academy of Sciences \\ Baku, Azerbaijan \\ ${ }^{4}$ Institue of Archaeology and Ethnography, Azerbaijan National Academy of Sciences \\ Baku, Azerbaijan \\ *Corresponding author's email: mammadov_sahib [AT] yahoo.com
}

\begin{abstract}
The radiocarbon dating method was used to date the age of a charcoal sample from the Polutepe archeological site in the Jalilabad district of Azerbaijan. Polutepe is the largest Neolithic-Eneolithic monument in the Caucasus. A charcoal sample excavated at the Polutepe site was dated by the conventional radiocarbon method at $4270 \pm 160 \mathrm{BC}$, which agrees with the stratigraphic estimated dates.
\end{abstract}

Keywords--- Radiocarbon dating, Archeology, Neolithic period, Polutepe, Mughan, Charcoal

\section{INTRODUCTION}

The study of the Neolithic-Eneolithic monuments in Mughan began in the 1960s and continued until 1979. A new stage in the study of the Mughan of the Neolithic-Eneolithic period was begun in 2004 by the author of this work. The work is being carried out in a complex interdisciplinary program, the ultimate goal of which is the preparation and publication of the work "Mughan in the VI-IV millennium BC." (to be published). At present, the Mughan NeolithicEneolithic expedition is carrying out archaeological research on the settlements of Polutepe and Alkhantepe. Despite being close in proximity to each other, these sites represent completely different ethno-cultural traditions and different stages of the studied epoch. Simultaneous study of genetically and chronologically different monuments located in the same territory has allowed for the revealing and tracing of more ethno-cultural aspects and other processes. Based on stratigraphic estimations, the age of the Neolithic-Eneolithic layer of the settlement of Polutepe is approximately from the end of the fifth to beginning of the fourth millennium BC.

Radiocarbon dating became as a wide spread conventional method for the dating of archaeological artifacts since it has been first applied by Libby in 1949. Application of this method enabled dating of human remains, bone ornaments and worked bone [1], establishing a chronology of Prehispanic ritual activities performed in the Nevado de Toluca [2], dating of rock art site in Parana State, South Brazil [3] and many more. The presented work is a first attempt to increase the accuracy of dating real archeological monuments, namely, Polutepe archeological site in Jalilabad district of Azerbaijan by the newly established radiocarbon dating group.

\subsection{Brief summary of the Polutepe archeological site}

It is located on the eastern outskirts of Uchtepe village of Jalilabad region, Azerbaijan Republic, on the right (southern) bank of the Injachai river (39 $19^{\prime} 37.67^{\prime \prime} \mathrm{N}, 48^{\circ} 27^{\prime} 05.71^{\prime \prime} \mathrm{E}$ ) at $38 \mathrm{~m}$ above sea level. It is a hill formed by cultural deposits on the practically flat southern bank of the Injachay River. Its area is about 6 hectares; the height on the north side of the bottom of the dry channel is $11 \mathrm{~m}$ and on the south side is $5 \mathrm{~m}$. At present, it is the largest NeolithicEneolithic monument in the area known as the Caucasus. The choice of this monument as a base for our studies was due primarily to the fact that it is considerably larger than all the monuments known in this area, and we perceive it to be the center of the nest of settlements. The site of the main excavation at Polutepe settlement is on the northern edge of its summit, where the edge of the riverside slope is somewhat concave. As a result of excavations conducted, it was established that the total thickness of the cultural layer on the archeological site is $7 \mathrm{~m}$ (Fig.1.). The upper $1 \mathrm{~m}$ layer 
represents the era of the developed Middle Ages (9th-11th centuries).The $6 \mathrm{~m}$ layer below that is composed of deposits from the Mughan Neolithic tradition. In the interval between these two layers, alluvial deposits of the Kur-Aras culture of the Early Bronze Age and individual findings of the Middle Bronze Age were revealed.

This shows that the surface of an abandoned Neolithic settlement was briefly used in the epochs of the Early and Middle Bronze Age until the foundation of the medieval settlement.

The cultural layer as a whole was relatively loose, clayey-ash, light grayish-yellow in color, with individual ash lenses and clay seals.

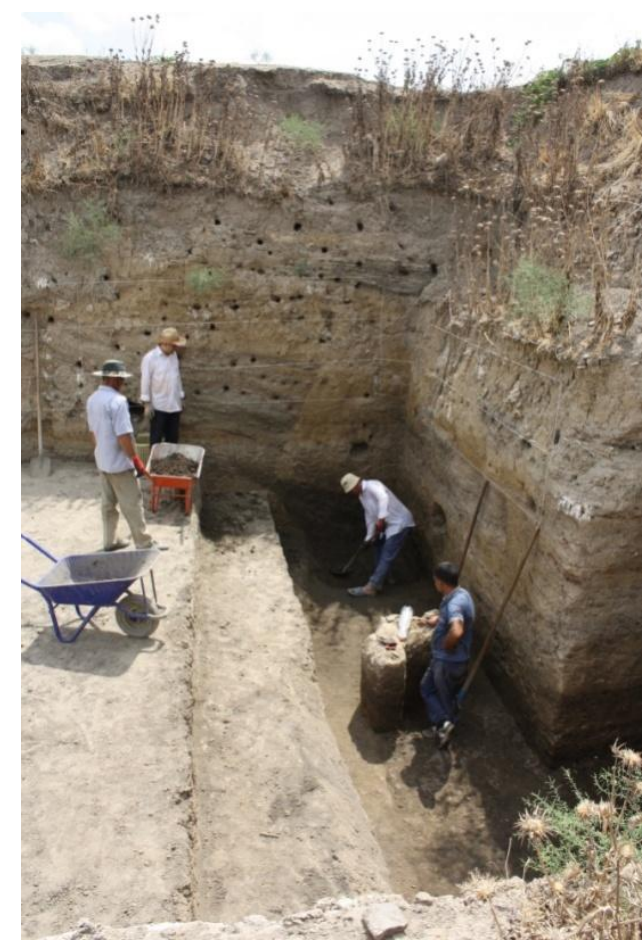

Figure 1 Polutepe archeological site

In the upper $3 \mathrm{~m}$ of the Neolithic deposits, there were no traces of brick or adobe buildings, although at various levels the remains of floors, burial sites, pottery furnaces and other diverse archaeological and osteological material of were discovered. This allows us to assume that in this $3 \mathrm{~m}$ thick layer, the structures were built from plant material with clay pugging.

The lower $3 \mathrm{~m}$ of the Neolithic layer contained the remains of various structures in a combination of rectangular and oval shapes. As a building material, raw rectangular bricks were used, with or without minuscule admixtures of plant material. The walls were erected with a thickness of one or two bricks. At various levels in the Neolithic layer, about two dozen remains of kilns for ceramic firing were found. They were generally two-tiered with an elongated combustion chamber and heat distribution arms, which were withdrawn to the upper calcination chamber. In rare cases, a square-shaped furnace with distribution hoses was found around the perimeter of the kilns. Also cleared from the site were more than two dozen anthropomorphic figures made of raw clay. Remains of burials were revealed at various sites and cultural levels. They represented different genders and ages, from infants to adults. The dead were buried on their left or right side in poorly-defined notches and without a certain orientation. In some cases, small cups and beads were found with the buried. Graves were sprinkled with red ocher.

In this rich archaeological site, ceramics prevailed. The number of ceramics exceeded those found in many Neolithic sites from other regions. Mainly fragments of ceramic vessels of various shapes, sizes, and functional purposes were found. A distinctive feature of the ceramic findings of Poltepe, like the entire Mughan Neolithic area, was a high number of painted ceramics. Along with these, the collection of findings included a large number of stone tools of various functions and rock types. For the production of plates, mostly local gray flint and very rarely imported obsidian were used. Basalt rocks were used to make axes. In addition, dense sandstone and river cobblestone were widely used for making tools. Bone, horn, and shells were used in the household and as tools, as well as for making ornaments. A copper bead was also found. Findings of osteological material showed that the inhabitants of the settlement, apart from farming, bred cattle and pigs. They engaged in fishing and hunting, and they kept dogs in the settlement

Charcoal for analysis was taken at the base of the furnace, at a depth of $6.3 \mathrm{~m}$ from the common reference point, $5.3 \mathrm{~m}$ into the Neolithic layer, and $0.7 \mathrm{~m}$ above the base of the settlement. . Based on the archaeological comparative analysis of the collection of the settlement of Poltepe, this monument is dated to the end of the V boundary of V-IV millennium $\mathrm{BC}$. 


\section{EXPERIMENT}

Radiocarbon dating was performed using the conventional benzene synthesis method as described by Tamers [4]. The assumption in carbon-14 dating is that the analyzed sample has undergone only radioactive decay within the years since it ceased interaction with the biosphere. However, the archaeological artifacts and geological specimens are usually found embedded in or contaminated by other carbon-containing materials, which affect the carbon-14 content of samples. The reliability of the dating of old charcoal samples depends on the chemical treatment of the sample to remove any external 14C while leaving reliable fractions for dating. Charcoal samples of 25 grams were treated by an acid-alkali-acid (AAA) pretreatment method after removal of visible contaminants. The concentration of the acid (HCI) and alkali $(\mathrm{NaOH})$ was $0.5 \%[5]$.

Benzene production is carried out by the following reactions:

$2 \mathrm{C}+2 \mathrm{Li}=\mathrm{Li}_{2} \mathrm{C}_{2}$

$\mathrm{Li}_{2} \mathrm{C}_{2}+\mathrm{H}_{2} \mathrm{O}=\mathrm{C}_{2} \mathrm{H}_{2}+\mathrm{Li}_{2} \mathrm{O}$

$3 \mathrm{C}_{2} \mathrm{H}_{2}=\mathrm{C}_{6} \mathrm{H}_{6}$

In order to remove possible ammonia compounds, acetylene was passed through phosphoric acid. A chromium activated alumina-silica catalyst was used for conversion of acetylene to benzene at room temperature. Benzene was then evaporated out of the catalyst at $120^{\circ} \mathrm{C}$ and collected in a vacuum at liquid nitrogen temperature. The synthesized benzene was transferred into $20 \mathrm{ml}$ low-potassium glass counting vials and increased to $3 \mathrm{ml}$ volume by adding petroleum-derived benzene. As a scintillation solution, $1 \mathrm{ml}$ of commercially available SIGMA-ALDRICH liquid scintillation mixture PPO/POPOP in toluene was added.

The information needed for radiocarbon measurement performed by decay counting is the measured specific activity of the sample, a standard, and a background sample. As a background, commercially available petroleum-derived (i.e. dead) benzene was used. The ${ }^{13} \mathrm{C}$ isotopic fractionation was taken into account by normalizing to -25 per mil with respect to Pee Dee Belemnite (PDB) [6], the postulated mean value of terrestrial wood, as we had yet not determined in our experiments the ${ }^{14} \mathrm{C}$ fractionation factor (i.e. ${ }^{13} \mathrm{C} /{ }^{14} \mathrm{C}$ ratio).

The counting vial was then transferred into the liquid scintillation analyzer Tri-Carb 3100TR and allowed to count for a period of 300 to 1000 minutes depending on the size, age, and precision requirements.

\section{RESULTS AND DISCUSSION}

Fig. 2 illustrates the part of the archeological site where the charcoal sample was excavated.

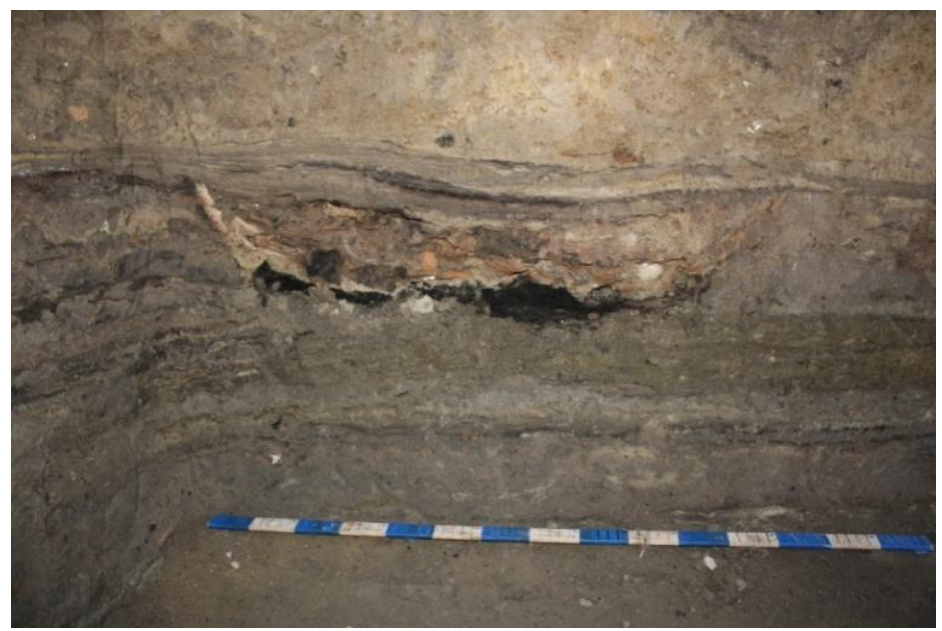

Figure 2. The furnace from which the charcoal sample was taken.

Approximately 50 grams of charcoal pieces were collected and cleaned from the surrounding soil and divided into three aliquots. After AAA treatment $(0.5 \%$ HCI and $0.5 \% \mathrm{NaOH})$, the loss of samples by weight was around $20 \%$.Conventional radiocarbon ages and sigmas were rounded to the nearest 10 years per the conventions of the 1977 International Radiocarbon Conference [7]. The reported measurement results were:

Percent modern carbon: $50.68 \pm 1.20 \mathrm{pMC}$

Fraction modern carbon: $0.5068 \pm 0.012$

D14C: $-492.92 \%$

Measured radiocarbon age: $5460 \pm 130$ years BP $(0=1950)$ 
Calibration was conducted with CalPal (version2016) downloaded from http://monrepos-rgzm.de/research-103/amenities.html (Fig.3).

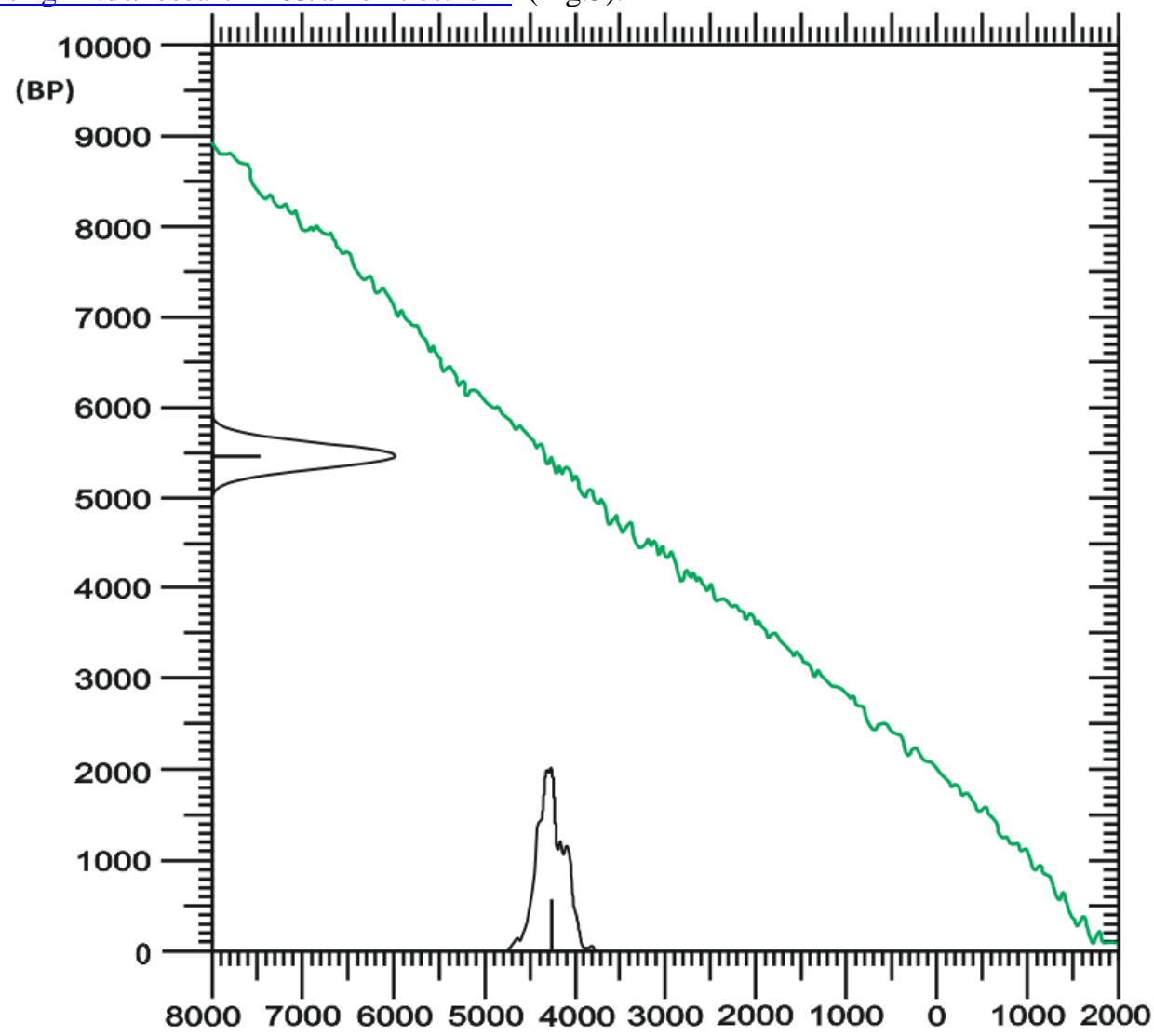

(cal BC/AD)

Figure 3. Calibration by CalPal (version 2016): Manropes radiocarbon calibration and paleoclimate research package. Database used INTCAL13 [8].

Calibration results with $68 \%$ probability were $4270 \pm 160 \mathrm{CalBC} / \mathrm{AD}$ and $6220 \pm 160 \mathrm{CalBP}(0=1950)$. Calibration results with $95 \%$ probability were $4590-3950 \mathrm{CalBC}$ and $6540-5900 \mathrm{CalBP}(0=1950)$.

\section{SUMMARY}

The Neolithic era as a whole was characterized by the presence of a large number of objects made from bone and horn. The settlements of the Mugan Neolithic site possess the same characteristics. A large number of bone and, to a lesser extent, horn products with functional purposes have been discovered. Piercings predominate and are mostly made from small-bodied tubular bones. In most cases, longitudinally split bone was used for this purpose, with preservation or removal of the epiphytic head and sharpening of the other end. Less often, the end of the tubular bone was obliquely cut and sharpened. Along with tubular bone, there are also piercings from other bones. Knife-like hollows also prevail, made of longitudinally cut scapula.

Based on the data obtained during the excavations, Mughan Neolithic diet was based on the cultivation of cereals, the maintenance of various types of domestic animals, hunting, and fishing. They wore soft, stubborn shoes, and they had dogs in the settlement.

As mentioned above, the Mughan Neolithic tradition represents a relatively late stage in this era. Comparison of the material obtained from here makes it possible to attribute this tradition from the late $\mathrm{V}$ to early IV millennium BC. Calibrated radiocarbon age of the charcoal sample taken from the pottery furnace was found to be from 4590-3950 BC. This indicates with $95 \%$ probability that the Polutepe archeological site truly dated from the late V to early IV millennium BC.

\section{REFERENCES}

[1]. Fewlass, H., Talamo, S., Tuna, T., Fagault, Y., Kromer, B., Hoffmann, H., Bard, E. (2017). Size Matters: Radiocarbon Dates of \&lt;200 $\mu \mathrm{g}$ Ancient Collagen Samples with AixMICADAS and Its Gas Ion Source. Radiocarbon, 60(2), 425-439. doi:10.1017/RDC.2017.98 
[2]. Martínez-Carrillo, M., Solís, C., Bautista, I., Sánchez, R., Rodríguez-Ceja, M., Ortiz, M., \& Chávez-Lomelí, E. (2017). Radiocarbon Dating of Underwater Archaeological Objects from the Nevado de Toluca, Mexico. Radiocarbon, 59(6), 1705-1712. doi:10.1017/RDC.2017.106

[3]. Lopes, F., Parellada, C., Gomes, P., Appoloni, C., Macario, K., Carvalho, C., . . Pessenda, L. (2017). Investigating a Rock Art Site in Paraná State, South of Brazil. Radiocarbon, 59(6), 1691-1703. doi:10.1017/RDC.2017.111

[4]. Tamers, M. (1975). Chemical Yield Optimization of the Benzene Synthesis for Radiocarbon Dating. International Journal of Applied Radiation and Isotops , 26, 676-682.

[5]. Zaitseva, G. (1995). Chemical Composition and Sample Preparation of Archaeological Wood for Radiocarbon Dating. Radiocarbon , 26 (2), 311-317.

[6], Stenstorm K.E., Skog G., Georgiadou E., Genberg J., Johanson A.,. (2011). A guide to radiocarbon units and calculations. Lund University, Internal Report LUNFD6 (NFFR-3111/1-17)(2011) , 1-17.

[7]. Millard, A. R. (2014). Conventions for reporting radiocarbon determinations. Radiocarbon , 56 (2), $555-559$.

[8]. Reimer, P. J., Bard, E., Bayliss, A., Beck, J. W., Blackwell, P. G., Bronk Ramsey, C., Buck, C. E., Edwards, R. L., Friedrich, M., Grootes, P. M., Guilderson, T. P., Haflidason, H., Hajdas, I., Hatt'e, C., Heaton, T. J., Hoffmann, D. L., Hogg, A. G., Hughen, K. A., Kaiser, K. F., Kromer, B., Manning, S. W., Niu, M., Reimer, R. W., Richards, D. A., Scott, E. M., Southon, J. R., Staff, R. A., Turney, C. S. M., and van der Plicht, J. (2013). IntCal13 and Marine13 radiocarbon age calibration curves 0-50,000 years cal BP. Radiocarbon, 55(4):1869-1887 